\section{Socio-economic impacts of COVID-19 in a one health}

\section{context}

\section{ABSTRACT}

The last decades experienced a significant increase in the number of infectious disease outbreaks while current economic systems put pressure on the environment and wildlife is being destructed, leading to species to live closer to each other and humans. These diseases including zoonoses cause loss of life and threaten economic development and the integrity of the ecosystems. The recent COVID-19 is a significant example of this situation with a dramatic loss of human life, devastating economies and causing social disruption. The COVID-19 pandemic has also threatened food security, putting millions of people at risk of hunger, disrupted food, and feed supply routes, put pressure on livestock industries, led to a decrease in world meat production, caused trade restrictions, changed consumer habits, affected animal health and animal welfare. In this study, the main drivers of zoonoses, socio-economic impacts of these zoonoses with an emphasis on the COVID-19 pandemic and the necessary actions that need to be taken to prevent further epidemics/pandemics have been discussed in the context of "One Health" approach.

Keywords: Covid-19, one health, preventive health, socio-economy, zoonotic diseases

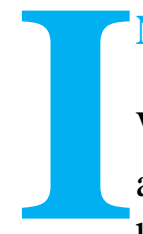

\section{NTRODUCTION}

While the COVID-19 pandemic has spread with a dramatic speed and caused devastating economic and social disruption, the world has already been confronted with a sudden increase in the number of infectious disease outbreaks in the last decades. World Health Organization (WHO) monitored 1483 epidemic events in 172 countries between the years 2011 and 2018. Some of these epidemic diseases such as influenza, Severe Acute Respiratory Syndrome (SARS), Middle East Respiratory Syndrome (MERS), Ebola, Zika, plague and Yellow Fever are fast-spreading and frequently being detected (GPMB, 2019). The global emergence of these diseases is notable in terms of existing human infections of which $60 \%$ is reported as zoonoses. Zoonoses are defined as diseases and infections naturally transmitted between people and vertebrate animals. $75 \%$ of 30 new human pathogens that have been detected in the last three decades have originated in animals. Around one billion cases of illness and millions of deaths occur every year from zoonoses globally (Jones et al., 2008). In 1918, "Spanish flu”, also known as the 1918 flu pandemic, have caused to illness of an estimated 500 million and death of as high as 50 million people (CDC, 2019). Since then, 2.5 billion cases and 2.7 million deaths are caused by zoonoses each year, having serious impacts on health and economies (Njenga, 2020).

\section{How to cite this article}

Erşan, I., Gökdai, A., Sakarya E. (2021). Socio-economic impacts of COVID-19 in a one health context. Journal of Advances in VetBio Science and Techniques, 6(2), 171-178. https://doi.org/10.31797/vetbio.880752
Review Article

Işık ERŞAN ${ }^{1 \mathrm{a}}$

Arzu GÖKDAI ${ }^{2 b}$

Engin SAKARYA ${ }^{2 c}$

${ }^{1}$ Ministry of Food, Agriculture and Livestock General Directorate of EU and External Relations,

Ankara, Turkey

${ }^{2}$ Department of Animal

Health Economics and

Management, Faculty of

Veterinary Medicine, Ankara University, Ankara, Turkey

ORCIDD-

a0000-0001-7816-904X

b0000-0002-5509-2171

c0000-0003-3569-3292

Correspondence

Arzu Gökdai

agokdai@ankara.edu.tr

Article info

Submission: 16-02-2021

Accepted: 27-04-2021

Online First: 28-05-2021

e-ISSN: 2548-1150

doi prefix: $10.31797 /$ vetbio

- http://dergipark.org.tr/vetbio

This work is licensed under a Creative Commons Attribution 4.0 International License (c) (i) 
Besides fatality, zoonoses jeopardize economic development and the integrity of the ecosystem. In the last twenty years, zoonotic diseases have caused more than $\$ 100$ billion economic losses, excluding the economic cost of the COVID-19 pandemic, which was foreseen to reach $\$ 9$ trillion over the next few years (UNEP, 2020). Economic impacts estimated for some of the past epidemics/pandemics are as such 2003 SARS epidemic costing of over US $\$ 40$ billion (Lee et al., 2004); 2014-2016 West Africa Ebola outbreak causing US $\$ 53$ billion loss (Huber et al., 2018), the 2009 H1N1 "Swine flu" pandemic causing an economic loss of US \$45 to 55 billion (GPMB, 2019). Between the years 2013 - 2014 in Liberia, Gross Domestic Product (GDP) growth declined from $8.7 \%$ to $0.7 \%$, due to Ebola and reducing commodity prices, and in Sierra Leone (excluding iron ore), GDP growth decreased from 5.3\% to $0.8 \%$ (Zafar et al.,2016). The total direct costs of H5N1 "Bird flu" outbreaks have gone beyond US \$20 billion since 2003 (Berthe et al., 2017).

Considering $60 \%$ of all human infections originate from animals, zoonotic outbreaks have serious economic impacts on the agricultural sector. Fifty percent of reported livestock losses are caused by zoonoses and zoonotic diseases have a higher percentage of animal slaughter (43\% of livestock losses) as part of disease control measures compared to other diseases (6\% of livestock losses) (Smith et al., 2019). The outbreaks of Ebola, MERS, and SARS devastated agricultural production in the regions that they were spread (Pu and Zhong, 2020).

The aim of this study is to discuss the main drivers of zoonoses, socio-economic impacts of these zoonoses with an emphasis on the COVID19 pandemic and the necessary actions that need to be taken to prevent further epidemics/pandemics in the context of "One Health" approach.
SOCIO-ECONOMIC IMPACTS of COVID-19

The COVID-19 pandemic has caused a dramatic loss of human life, leading millions of enterprises face an existential danger, putting 3.3 billion workforces at risk of losing their incomes and bringing economic activity to a nearstandstill as governments implied movement restrictions to prevent the virus to spread (Chriscaden, 2020, World Bank, 2020). Millions of people are facing the threat of extreme poverty and the number of undernourished people could increase by 132 million more in 2020 (FAO, 2020a).

The World Bank estimated that the global economy has contracted $4.3 \%$ in 2020. In advanced economies, the initial contraction was not as severe as expected, but the following recovery has been reduced by re-emergence of COVID19 cases. Meantime, output in China has recovered faster than anticipated due to a particular support from infrastructure spending. China's situation was a special case, disruptions from the pandemic in most of the emerging markets and developing economies were more severe than expected and resulted in deeper recessions and slower recoveries. (World Bank, 2021). As stated by the Economic Commission for Latin America and the Caribbean, COVID19 will conclude the worst economic and social crisis in decades in the region, with a drop of GDP of -5.3 percent, poverty rate in the region could increase by up to $4.45 \%$ points during 2020, which means 2.936 million people (FAO, 2020b).

\section{IMPACT of THE COVID-19 on LIVESTOCK and AGRICULTURE SECTOR}

Unlike other infections like the Foot and mouth disease, Avian influenza, E. coli or Listeriosis, the COVID-19 pandemic has not spread directly through livestock and therefore has not directly caused disturbance in food production at farm level. On the other hand, the crisis is threatening the ability of farms to maintain food supply to markets due to closures, work force deficiency 
caused by illness and delays in operations due to physical distance and lockdown measures. These factors compromise the capacity of agricultural and food enterprises to carry out operations as always and putting at risk the survival of small agri-food enterprises including farms, traders, manufacturers, distributors, and retailers (FAO, 2020c). The shrinkage in sales due to the COVID-19 has led to increases in factors such as financing cost, logistics, storage, labor, energy, packaging, and distribution. In animal products, significant increases were observed in both sales prices and total costs during this period.

In many countries the COVID-19 spread rapidly between workers in processing plants. There are reports of clusters of COVID-19 cases in these enterprises in many countries such as in Germany, the disease affected at least 1,500 workers in one of the EU's biggest meat processors while in the U.S., there had been more than 39,000 reported positive cases related to meatpacking enterprises as of September 11, 2020 (Marchant- Forde and Boyle, 2020). These outbreaks might be caused by factors such as cold and damp indoor areas are appropriate environments for this virus to spread, the difficulty of workers to stay two meters apart while carrying out operations rapidly moving production lines, and the lack of daylight might be helping the coronavirus to survive (Reuben, 2020). Eighteen processing plants in the United States were closed, that affects more than a third of the beef and pork supply of the country (Felix et al., 2020).

Bovine meat output in the U.S. is predicted to conclude in 2020 with a $5 \%$ overall contraction because of labor shortages in meat processing. Not only a decrease of bovine meat especially in the USA and Australia, but also COVID-19 is having a global impact on every meat type as the world meat output was also forecast to fall in 2020 to 333 million tons, $1.7 \%$ less than 2019 . The contraction would also reflect a decrease in production of pig meat again, mainly in Asian countries with African swine fever outbreaks
(FAO, 2020d). There are news reporting milk industry had also been affected by the crisis, as there have been news reported that in the U.S. farmers had to dispose of 14 million liters of milk every day caused by the disruption of supply routes (BBC, 2020). Disruption of supply routes also caused delays for feed sector. In Argentina, which is the top soymeal exporter country, restrictions have decreased soy supply to feed factories considerably (FAO, 2020e).

The current Covid-19 crisis has also affected the consumer habits. Most of the food purchases have now shifted to the supermarkets with the shutdown of cafes, restaurants, canteens and also more people working from home (Hobbs, 2020). Per-capita meat consumption this year is the lowest in nine years and the $3 \%$ decline from last year represents the biggest drop since at least 2000 (FAO, 2020d). In the European Union, pork consumption was predicted to fall to a seven-year low in 2020. In China, the news report that there is growing distrust over animal products after the government suggested a link between imported protein and an outbreak in Beijing (Almeida et al., 2020). French shoppers have been choosing more organic food since the start of the pandemic fears took hold of the country (BBC, 2020). Sales of plant-based meat products were increased $264 \%$ during a nineweek period from March to April 2020 in the U.S (Lyons, 2020). There has been an increase in egg and poultry meat consumption during lockdowns due to low prices, easy and fast preparation at home etc. (Hafez and Attia, 2020).

Demand have shifted away from higher value items and towards staple and ready-to-eat foods that are available to be stored and there has been a strong increase in online commerce (OECD, 2020). Demand for non-food agricultural products such raw fur skins or wool dropped notably, while increased for staple food, processed fruits and vegetables which reflects the initial panic buying and increase in the homebased consumption. The current pandemic put more downward pressure on world food prices, 
which were already on a downward trend at the beginning of 2020, and producer revenues (WTO, 2020).

The beginning of the COVID-19 crisis has led to the governments panic about preserving their own food sources and disrupted global supply chains. As the top global wheat exporter Russia limited its grain exports from April to June 2020, the top global wheat importer Egypt stopped exports of legumes. In Argentina, which is the world's largest soybean products exporter, the roads in soybean production areas were temporarily closed, leading to the country's grain supplies reducing by half until the restrictions were loosened (Torero, 2020). Canadian imports of onions and eggplants from India decreased by $80 \%$ in two weeks as air cargo space diminished gradually (Jadhav et al., 2020). Measures implied by governments to control the pandemic have led disruptions to transport and logistics services. Border closures and social distancing requirements, which led to reducing the numbers of inspectors at borders, have increased the duration of customs clearance, and have led to retards, affecting the transit of perishable products (OECD, 2020).

As the crisis might have possible consequences on creating food security risks it might have an impact on animal health as well since veterinary practice have also been affected by the current crisis. According to a survey among practice owners in the U.S. in April 2020, about half of the veterinarians who participated the survey had client visits declined by $50 \%$ (AVMA, 2020). According to another survey, which was conducted with 3,258 pet owners from Brazil, the U.S., France, and the UK, more than a quarter of pet owners $(27 \%)$ delayed or avoided contacting their veterinary practice since the beginning of the Covid-19 pandemic (HealthforAnimals, 2020).

The pandemic also affected animal health in terms of spreading between minks which are farmed for fur production. In Denmark SARS-
CoV-2 infection was introduced into mink populations. Scientific investigations also have confirmed that SARS-CoV-2 infection has been reintroduced from mink to humans (OIE, 2021).

Animal welfare problems also occurred due to human cases which points the importance of One Welfare concept along the One Health approach. Since many processing plants were closed because of the clusters among the labors, this situation put pressure on pig and poultry industries. In the U.S., $45 \%$ drop in the capacity for pig processing which results 250,000 pigs are not being slaughtered daily, also led to longer transport routes to the plants in function and overcrowding of animals on farm. Some of the pig producers had to cull animals on farm with practices that made the animals feel more pain (Marchant- Forde and Boyle, 2020).

\section{COVID-19 and ENVIRONMENT}

This pandemic is reminding us our deteriorated relation with nature as the economic systems are putting pressure on the environment. In the last 50 years, $60 \%$ of all wildlife was lost, while the number of emerging diseases has become four times more than in the last 60 years. It is not a coincidence that ecosystem devastation has concurred with a significant boost in these infections. Natural habitats are being destroyed, leading to species to live more closely to each another and to humans, therefore risking that viruses find humans as new hosts, especially as the natural disease resistance which might result from biodiversity is lost (Quinney, 2020). Ecosystem integrity can help controlling diseases through supporting a diversity of species so that it is more difficult for one pathogen to spread faster or dominate (UNEP, 2016).

Land-use and agricultural industry changes are globally the top drivers of zoonoses. Changes in human host behaviors such as travel, conflicts and migration, wildlife trade, globalization, urbanization, and dietary preferences are also drivers of emerging zoonotic diseases (Loh et al., 
2015). Deforestation of land has been related to increased malaria rates, outbreaks of Ebola, Lyme disease and Rabies while Human Nipah virus, was related to intensive of pig farming and Avian Infl $\neg$ uenza was related to intensive poultry production (UNEP, 2016). SARS-CoV2, the coronavirus which caused the COVID-19 pandemics, is closely linked genetically to coronaviruses isolated from bat populations. SARS-CoV, which is the pathogen that caused the SARS outbreak in 2003, is also closely linked to coronaviruses isolated from bats (WHO, 2020).

While many of these recent events have been caused by environmental degradations, these diseases have impacts on the environment as well. The Covid-19 pandemics have affected the environment in both positive and negative ways.

According to the NASA, deforestation degrees are changing in some regions, air pollution is declining, quality of water is advancing, and snow is becoming more reflective in some places since the beginning of the pandemic (Bates, 2020). After increasing for decades, global carbon dioxide emissions dropped by $6.4 \%$, or 2.3 billion tons, in 2020 , as the COVID-19 pandemic suppress economic and social activities (Tollefson, 2021). Emissions from road transport and aviation account for the largest share of the global decrease, due to the restrictions of governments.

The decline of emissions appears more in the US $(-12 \%)$ and EU27 countries $(-11 \%)$ and least pronounced in China $(-1.7 \%)$ (UEA, 2020). According to the World Air Quality Index, air quality (NO2, CO, PM2.5, and O3) data for the January 2019-April 2020 period, shows there was a significant decrease in the levels of NO2, $\mathrm{CO}$, and PM in 2020, compared to their levels in 2019 (Habibi et al., 2020). The observations of global nitrogen dioxide (NO2) during March, April, and May 2020, have revealed reductions between $10 \%-30 \%$ in polluted areas of Europe, North America, and Asia (EC, 2020). This drop in NO2 is related to the significant decline in land and air transportation, industry, and electricity generation during the lockdown. According to analyses carried out in some European cities including Dublin, Madrid, Rome and Brussels, there has been a significant reduction in sound levels or noise due to reduction in road and air traffic (Aletta et al., 2020, Asensio et al., 2021, Basu et al., 2021, Gibney, 2020).

The first studies on water quality suggest an improvement resulting from the lockdowns. The pollutants' concentration in the Vembanad Lake, which is the longest lake in India, dropped by $16 \%$ compared to the previous year (Yunus et al., 2020). On the other hand, an increase in the concentrations of microplastics in the waters is also possible, since from the beginning of the COVID-19 outbreak plastic-based personal protective equipment production has increased rapidly (Singh et al., 2020, Tedesco, 2020). As the consumer demand for e-commerce and home delivery increased globally as a result of lockdown, waste generation has increased. However, waste management and recycling activities has been limited because of disease control measures in many countries (ZambranoMonserrate et al., 2020).

\section{GENERAL EVALUATION and} CONCLUSION

The COVID-19 pandemic has highlighted the importance of a One Health approach, which recognizes the health of people, animals and the environment are closely interconnected, as the solution to reduce the threat of possible pandemics in the future. This approach has gained importance in recent years due to the changes in interactions between people, animals and the environment that have led to emerging and re-emerging global diseases. Generally, environment health initiatives have been less represented than animal, livestock, and human health initiatives in global programs for the prevention and control of zoonoses. However, 
environment is crucial for the One Health approach since land use change is the top driver to new outbreaks of zoonoses. Landscape policies and investments should be made with a One Health approach to take the opportunities to address the biggest challenges of our time (Njenga, 2020).

Likewise, animal health is an important component of the One Health approach and therefore Veterinary Services should have to cooperate and collaborate with Public Health authorities and those responsible for wildlife, to reduce the impact of the COVID-19. There are good examples of this approach, such as Veterinary Services in some countries have supported the public health services by testing samples from humans, while in some other countries veterinary practitioners have donated their protective equipment and ventilators. According to the OIE, Veterinary Services should be considered as essential services and national authorities should continue in the activities related to animal health, welfare and veterinary public health, under appropriate protocols (OIE, 2021).

Global based analyses suggest high return on investment in human and animal health systems in low- and middle-income countries to prevent possible future pandemics and epidemics, assume that US $\$ 1.8$ billion to US $\$ 4.5$ billion annual expenditure would result as a benefit between US \$30-60 billion per year in avoided cost (Machalaba et al., 2017).

Nature provides extensive opportunities for businesses and governments since every dollar invested in restoration of nature could provide minimum $\$ 9$ of economic benefits (Nature4Climate, 2020). In addition, shifts in farming and food production practices could reveal \$4.5 trillion a year in business opportunities by 2030 and save trillions of dollars economic cost caused by social and environmental harms (FOLU, 2019).
Pointing to the likely cost of COVID-19 of $\$ 8-16$ trillion globally by July 2020 , estimations suggest that costs in the U.S. might be up to $\$ 16$ trillion by the end of 2021. The experts estimate the cost of reducing risks to prevent pandemics is 100 times less costly than responding to these pandemics, highlighting the importance of "providing strong economic incentives for transformative change" (Rukikaire, 2020).

Recent studies have estimated that the cost of preventing further pandemics over the next decade by protecting wildlife and forests equates to just $2 \%$ of the financial damage caused by the COVID-19 (Dobson et al., 2020).

Even though the impact of the pandemic will differ between countries, it will probably increase poverty and inequalities globally and will make achieving the "Sustainable Development Goals" of the United Nations more crucial and urgent than ever (UN, 2020). It is also an opportunity to advance transformations in the food and agriculture sector to make it more resilient to the challenges in the future such as climate change (OECD, 2020).

Therefore, policymakers need to consider close interactions between humans, animals and ecosystem with the "One Health" approach and take into account "Prevention is better than cure" approach for health policies and investments in order to be prepared for the future challenges and to help sustainable and equitable distribution of resources.

\section{ACKNOWLEDGMENT}

On behalf of all the co-authors hereby, I declare that the manuscript entitled "Socio-economic Impacts of COVID-19 in a One Health Context" does not require the ethical statement.

\section{REFERENCES}

Aletta, F., Brinchi, S., Carrese, S., Gemma, A., Guattari, C., Mannini, L., \& Patella, S. M. (2020). Analysing urban traffic volumes and mapping noise emissions in Rome (Italy) in the context of containment measures for the COVID-19 disease. Noise Mapping, 7(1), 114-122. 
Almeida, I., Durisin, M., Freitas, T., Rembert, E., Niu, S., Hirtzer, M., \& de Sousa, A. (2020). Pandemic to Spark Biggest Retreat for Meat Eating in Decades. Bloomberg News. https://www.bloomberg.com/news /articles/2020-07-07/pandemic-set-to-spark-biggestretreat-for-meat-eating-in-decades.

Asensio, C., Pavón, I., \& De Arcas, G. (2020). Changes in noise levels in the city of Madrid during COVID-19 lockdown in 2020. The Journal of the Acoustical Society of America, 148(3), 1748-1755.

AVMA, (2020). COVID-19 impact on veterinary practices. $\quad$ https://www.avma.org/resources-tools /animal-health-and-welfare/covid-19/covid-19impact-veterinary-practices.

Basu, B., Murphy, E., Molter, A., Basu, A. S., Sannigrahi, S., Belmonte, M., \& Pilla, F. (2021). Investigating changes in noise pollution due to the COVID-19 lockdown: The case of Dublin, Ireland. Sustainable Cities and Society, 65, 102597.

Bates, S. (2020). AGU Panel Explores Environmental Impacts of the COVID-19 Pandemic, as Observed from Space. NASA. https://www.nasa.gov/feature /goddard/2020/agu-panel-explores-environmentalimpacts-of-the-covid-19-pandemic-as-observed-fromspace.

BBC, (2020). Coronavirus: Five ways the outbreak is hitting global food industry. https://www.bbc.com/news/world-52267943.

Berthe, F., Bouley, T., \& Osewe, P. (2017). One health economics for healthy people, agriculture and environment. World Bank. https://blogs. worldbank.org/health/one-health-economics-healthypeople-agriculture-and-environment.

CDC, (2019). Centers for Disease Control and Prevention. https://https://www.cdc.gov/flu/pandemic resources/1918-pandemic-h1n1.html.

Chriscaden, K. (2020). Impact of COVID-19 on people's livelihoods, their health and our food systems. WHO. https://www.who.int/news/item/13-10-2020-impact-of -covid-19-on-people's-livelihoods-their-health-andour-food-systems.

Dobson, A. P., Pimm, S. L., Hannah, L., Kaufman, L., Ahumada, J. A., Ando, A. W., Bernstein, A., Busch, J., Daszak, P., Engelmann, J., Kinnaird, M.F., Li, B.V., Loch-Temzelides, T., Lovejoy, T., Nowak, K., Roehrdanz, P.R., \& Vale, M. M. (2020). Ecology and economics for pandemic prevention. Science, 369(6502), 379-381.

EC, (2020). Lower air pollution during COVID-19 lockdown may improve crop production. European Commission. https://ec.europa.eu/jrc/en/news/lowerair-pollution-during-covid-19-lockdown-mayimprove-crop-production.

FAO, (2020a). Impact of COVID-19 on people's livelihoods, their health and our food systems. http://www.fao.org/news/story/en/item/1313598/icode

FAO, (2020b). Coronavirus disease 2019 (COVID-19). Addressing the impacts of COVID-19 in food crises April-December 2020. FAO's component of the Global COVID-19 Humanitarian Response Plan. http://www.fao.org/3/ca8497en/CA8497EN.pdf
FAO, (2020c). Adjusting business models to sustain agrifood enterprises during COVID-19. http://www.fao .org/3/ca8996en/CA8996EN.pdf.

FAO, (2020d). Food Outlook Biannual Report on Global Food Markets. http://www.fao.org/3/ca9509en/ CA9509EN.pdf.

FAO, (2020e). Mitigating the impacts of COVID-19 on the livestock sector. http://www.fao.org/3/ca8799en /CA8799EN.pdf.

Felix, I., Martin, A., Mehta, V., \& Mueller, C. (2020). US food supply chain: Disruptions and implications from COVID-19. McKinsey\&Company. https://www. $\underline{\text { mckinsey.com/industries/consumer-packaged-goods }}$ lour-insights/us-food-supply-chain-disruptions-andimplications-from-covid-19.

FOLU, (2019). The Global Consultation Report of the Food and Land Use Coalition. https://www.foodandlandusecoalition.org/wp-content/ uploads/2019/09/FOLU-GrowingBetter GlobalReport.pdf.

Gibney, E. (2020). Coronavirus lockdowns have changed the way Earth moves. Nature. https://www. nature.com/articles/d41586-020-00965-x.

GPMB, (2019). Annual report on global preparedness for health emergencies. https://apps.who.int/gpmb/ assets/annual_report/GPMB Annual_Report_English. pdf

Habibi, H., Awal, R., Fares, A., \& Ghahremannejad, M. (2020). COVID-19 and the Improvement of the Global Air Quality: The Bright Side of a Pandemic. Atmosphere, 11(12), 1279.

Hafez, H. M., \& Attia, Y. A. (2020). Challenges to the poultry industry: current perspectives and strategic future after the COVID-19 outbreak. Frontiers in veterinary science, 7 .

HealthforAnimals, (2020). Survey of Pet Owners Shows Impacts of Covid-19 Pandemic on Veterinary Care. https://healthforanimals.org/resources-and-events/ newsletter-repository/39-pet-owner-survey.html?q= $\underline{116 .}$.

Hobbs, J. E. (2020). Food supply chains during the COVID-19 pandemic. Canadian Journal of Agricultural Economics/Revue canadienne d'agroeconomie, 68(2), 171-176.

Huber, C., Finelli, L., \& Stevens, W. (2018). The economic and social burden of the 2014 Ebola outbreak in West Africa. The Journal of Infectious Diseases, 218(Supplement_5), S698-S704.

Jadhav, R., Thukral, N., \& Hunt, N. (2020). Coronavirus upends global food supply chains in latest economic shock. Reuters. https://www.reuters.com/article/us-health-coronavirus -food-supplies-insi-idUSKBN21L2V7.

Jones, K. E., Patel, N. G., Levy, M. A., Storeygard, A., Balk, D., Gittleman, J. L., \& Daszak, P. (2008). Global trends in emerging infectious diseases. Nature, 451(7181), 990-993.

Lee, J. W., \& McKibbin, W. J. (2004). Estimating the global economic costs of SARS. In Learning from SARS: preparing for the next disease outbreak: workshop summary (pp. 92-109). Washington, DC: National Academies Press. 
Loh, E. H., Zambrana-Torrelio, C., Olival, K. J., Bogich, T. L., Johnson, C. K., Mazet, J. A., Karesh, W., \& Daszak, P. (2015). Targeting transmission pathways for emerging zoonotic disease surveillance and control. Vector-Borne and Zoonotic Diseases, 15(7), 432-437.

Lyons, K. (2020). Plant-based meat sales in the US are up 264 percent since March. The Verge. https://www.theverge.com/2020/5/15/21259997/plant -based-meat-coronavirus-impossible-beyond.

Machalaba, C., Smith, K. M., Awada, L., Berry, K., Berthe, F., Bouley, T. A., Bruce, M., Cortiñas Abrahantes, J., El Turabi, A., Feferholtz, Y., Flynn, L., Fournié, G., Andre, A., Grace, D., Jonas, O., Kimani, T., Le Gall, F., Jose Miranda, J., Peyre, M., Pinto, J., Ross, N., Rüegg, S.R., Salerno, R.H., Seifman, R., Zambrana-Torrelio, K., \& Karesh, W. B. (2017). One Health Economics to confront disease threats. Transactions of The Royal Society of Tropical Medicine and Hygiene, 111(6), 235-237.

Marchant-Forde, J. N., \& Boyle, L. A. (2020). COVID19 effects on livestock production: A One Welfare issue. Frontiers in veterinary science, 7, 734.

Nature4Climate, (2020). Nature4Climate Report. https://nature4climate.org/restoration-andmanagement/.

Njenga, G. (2020). Mitigating future pandemics through a One Health approach. ILRI. https:// https://www.ilri.org/news/mitigating-futurepandemics-through-one-health-approach.

OECD, (2020). COVID-19 and the Food and Agriculture Sector: Issues and Policy Responses. https://www.oecd.org/coronavirus/policy-responses/ covid-19-and-the-food-and-agriculture-sector-issuesand-policy-responses-a23f764b/.

OIE, (2021). Questions and Answers on COVID-19. https://www.oie.int/scientific-expertise/specificinformation-and-recommendations/questions-andanswers-on-2019novel-coronavirus/.

Pu, M., \& Zhong, Y. (2020). Rising concerns over agricultural production as COVID-19 spreads: Lessons from China. Global food security, 26, 100409.

Quinney, M. (2020). COVID-19 and nature are linked. So should be the recovery. World Economic Forum. https://www.weforum.org/agenda/2020/04/covid-19nature-deforestation-recovery/.

Reuben, A. (2020). Coronavirus: Why have there been so many outbreaks in meat processing plants? BBC. https://www.bbc.com/news/53137613.

Rukikaire, K. (2020). Escaping the 'Era of Pandemics': Experts warn worse crises to come options offered to reduce risk. UN. Environment Programme. https://www.unep.org/news-and-stories/pressrelease/escaping-era-pandemics-experts-warn-worsecrises-come-options.

Singh, N., Tang, Y., \& Ogunseitan, O. A. (2020). Environmentally sustainable management of used personal protective equipment. Environmental science \& technology, 54(14), 8500-8502.

Smith, K. M., Machalaba, C. C., Seifman, R., Feferholtz, Y., \& Karesh, W. B. (2019). Infectious disease and economics: The case for considering multisectoral impacts. One Health, 7, 100080.
Tedesco, M. (2020). Coronavirus Is Improving Water Quality - For Now, At Least. State of the Planet. Earth Institute. Columbia University. https://blogs.ei.columbia.edu/2020/06/08/coronavirusimproving-water-quality/.

Tollefson, J. (2021). COVID curbed carbon emissions in 2020- but not by much. Nature. https://www.nature.com/articles/d41586-021-000903.

Torero, M. (2020). How to Stop a Looming Food Crisis. Foreign Policy News. https://foreignpolicy.com/2020/04/14/how-to-stopfood-crisis-coronavirus-economy-trade/.

UEA, (2020). Covid Lockdown Causes Record Drop In Co2 Emissions 2020.

https://www.uea.ac.uk/news/-/article/covid-lockdowncauses-record-drop-in-co2-emissions-for-2020.

UN, (2020). A UN framework for the immediate socioeconomic response to COVID-19. https://unsdg.un.org/sites/default/files/2020-04/UNframework-for-the-immediate-socio-economicresponse-to-COVID-19.pdf.

UNEP, (2016). Zoonoses: Blurred Lines of Emergent Disease and Ecosystem Health. https://wedocs.unep.org/bitstream/handle/20.500.1182 $\underline{2 / 32060 / \text { zoonoses.pdf? sequence }=1 \& \text { is Allowed }=y}$.

UNEP, (2020). Unite human, animal and environmental health to prevent the next pandemic - UN Report. https://www.unenvironment.org/news-and-stories/ press-release/unite-human-animal-and-environmentalhealth-prevent-next-pandemic-un.

WHO, (2020). Origin of SARS-CoV-2. https://apps.who.int/iris/bitstream/handle/10665/3321 97/WHO-2019-nCoV-FAQ-Virus origin-2020.1eng.pdf.

World Bank, (2020). The Global Economic Outlook During the COVID-19 Pandemic: A Changed World. https://www.worldbank.org/en/news/feature/2020/06/ 08/the-global-economic-outlook-during-the-covid-19pandemic-a-changed-world.

World Bank, (2021). Global Economic Prospects. A World Bank Group Flagship Report.

WTO, (2020). WTO issues new report regarding impact of COVID-19 crisis on agricultural trade. World Trade Organization News. https://www.wto.org/ english/news_e/news20_e/agri_27aug20_e.htm.

Yunus, A. P., Masago, Y., \& Hijioka, Y. (2020). COVID-19 and surface water quality: Improved lake water quality during the lockdown. Science of the Total Environment, 731, 139012.

Zafar, A., Talati, C., \& Graham, E. (2016). 2014-2015 West Africa Ebola Crisis: Impact Update. World Bank. https://www.worldbank.org/en/topic/macroeconomics /publication/2014-2015-west-africa-ebola-crisisimpact-update.

Zambrano-Monserrate, M. A., Ruano, M. A., \& Sanchez-Alcalde, L. (2020). Indirect effects of COVID-19 on the environment. Science of the Total Environment, 728, 138813. 